\title{
Laparoscopic robotic-assisted gastrointestinal surgery: the Geneva experience
}

\author{
Claudio Soravia $\cdot$ Ian Schwieger $\cdot$ Jacques-Alain Witzig $\cdot$ Frank-Alain Wassmer $\cdot$ \\ Thierry Vedrenne $\cdot$ Pierre Sutter $\cdot$ Jean-Philippe Dufour $\cdot$ Yves Racloz
}

Received: 1 October 2007 / Accepted: 5 December 2007 / Published online: 4 January 2008

(C) Springer London 2007

\begin{abstract}
The continuing development of robotic surgery supports its use in laparoscopic gastrointestinal surgery. Our study retrospectively reviewed the surgical outcome and patient's satisfaction of gastrointestinal laparoscopic robotic procedures. From January 2003 to September 2007, 94 patients (27 women, 67 men) with a mean age of 53 years (range 19-84 years) underwent laparoscopic surgery with a da Vinci robotic system. There were 40 colorectal cases (43\%), 31 anti-reflux surgery cases $(33 \%)$ and 14 obesity surgery cases (15\%); the remaining cases consisted of gastric and gallbladder surgery, intra-abdominal tumour excisions, and hepatic cyst resections. The majority of the cases $(88,94 \%)$ were performed for benign disease.
\end{abstract}

\section{F.-A. Wassmer is deceased.}

\section{Soravia $(\bowtie)$}

Laparoscopic Robotic Surgery,

University of Geneva, Geneva, Switzerland

e-mail: csoravia@hin.ch

J.-A. Witzig · F.-A. Wassmer · Y. Racloz

Laparoscopic Robotic Surgery,

Clinique Générale-Beaulieu, Geneva, Switzerland

\section{Schwieger}

Department of Anesthesiology, University of Geneva,

Geneva, Switzerland

P. Sutter - J.-P. Dufour

Department of Anesthesiology, Clinique Générale-Beaulieu,

Geneva, Switzerland

T. Vedrenne

Department of Medical Computing,

Clinique Générale-Beaulieu, Geneva, Switzerland

C. Soravia $\cdot$ I. Schwieger

Clinique Générale-Beaulieu, Geneva, Switzerland
The mean operative time was $153 \mathrm{~min}$ (range 60-330 min). One patient needed a blood transfusion. The mean body mass index was 25 (range 16-47). No death occurred. Five cases $(5.3 \%)$ were converted to conventional laparoscopic surgery $(n=3)$ or to laparotomy $(n=2)$. Morbidity consisted of one Nissen redo surgery to loosen a tight anti-reflux valve 6 days after robotic surgery, a robotic left ureter repair and pelvic haemorrhage following proctectomy requiring re-operation to control haemostasis and to remove pelvic haematoma. Mean follow-up time was 11 months (range 15 days to 34 months). One case of incisional trocar hernia needed re-operation. Overall patient's satisfaction was high: few scars were cheloïd, while functional surgical outcome was rated high by most of the patients. Our preliminary experience was encouraging, with minimal morbidity and very high acceptance by patients.

Keywords Colon - Colorectal cancer .

Diverticular diseases - Gastric banding ·

Gastro-esophageal reflux diseases · Nissen fundoplication · Obesity surgery $\cdot$ Rectum $\cdot$ Robotic surgery

\section{Introduction}

In 1987, the first laparoscopic cholecystectomy was performed by P. Mouret [1]. Ten years later, Himpens et al. performed the first robotic cholecystectomy using a prototype system with remote control and a three-dimensional viewing through the use of specially developed glasses [2].

More sophisticated robotic systems were later developed which provided - or improved upon - a stable camera platform, three-dimensional imaging, excellent ergonomics, instruments with a wide-range degree of freedom and modulation of motion amplitude with tremor filtering. The 
current da Vinci robotic system (Intuitive Surgical, Sunnyvale, CA) is the most highly used system worldwide. The first da Vinci system was installed in Geneva in 2003, and to the best of our knowledge, our team has had the most experience among Swiss clinicians in gastrointestinal cases using this system.

The aim of the study reported here was to determine surgical feasibility, evaluate functional outcome and assess patients' satisfaction using this system.

\section{Material and methods}

To date, 94 consecutive patients have been treated by our team. From January 2003 to December 2006, the three-arm da Vinci system was used (73 cases), and from January 2007 to September 2007, our team used the four-arm da Vinci system (21 cases). During the entire study period, 409 robotic procedures were performed at our institution, consisting of 300 urologic cases (73\%), 94 gastrointestinal cases (23\%) and 15 gynecologic cases (4\%). Each patient's data were prospectively collected using a robotic logbook; a clinical information sheet for each individual was filled up by the surgeon and anesthesiologist and later stored in our computerized database system. A retrospective analysis was then performed to retrieve data. The follow-up was done during a patient's visit to the attending physician and/ or telephone interview. The patient's evaluation was obtaining using a visual analog score (1-10). Approval by our local Ethics Committee was obtained prior to carrying out this study.

\section{Results}

They were 27 men (29\%) and 67 women $(71 \%)$ in our patient cohort, with a mean age of 53 years (range 1984 years). Overall, mean hospital stay was 7 days (range 224 days), and mean body mass index (BMI) was 25 (range 16-47). A blood transfusion was needed in one case (1\%). Benign cases accounted for 88 patients (94\%). Only six patients $(6 \%)$ had malignant diseases: five colorectal adenocarcinomas and one intra-abdominal teratoma. The surgical procedures consisted of 40 colorectal cases (43\%), 31 anti-reflux cases (33\%), 14 morbid obesity cases (15\%) and nine miscellaneous cases (10\%).

Colorectal procedures consisted of sigmoidectomy $(n=20)$, sigmoidectomy and rectopexy $(n=8)$, right colectomy $(n=3)$, rectopexy $(n=3)$, low anterior resection $(n=2)$, caecectomy $(n=1)$, anterior resection $(n=1)$, abdomino-perineal resection $(n=1)$ and resection of rectovaginal endometriosis nodule $(n=1)$. Diagnoses prior to the surgical procedure were: diverticular disease $(n=20,50 \%)$, rectal prolapse $(n=11,27.5 \%)$, adenocarcinoma $(n=6$, $15 \%)$, benign multiple polyp or endoscopically non-resectable polyp $(n=2,5 \%)$ and recto-vaginal endometriosis $(n=1,2.5 \%)$. The mean age of patients undergoing colorectal procedures was 60 years (range $32-84$ years). The mean hospital stay was 9 days (range 3-24), and the mean BMI was 22 (range 19-40). Mean operative time was 162 min (range 60-330 min). Two patients were re-operated (one for a left ureter injury in which a robotic suture was performed, another for pelvic bleeding by conventional laparoscopy). There were three conversions to laparoscopy (two cases for difficult dissection, one for a robotic technical problem) and two conversions to laparotomy (one robotic technical problem, and one difficult dissection). Finally, one patient developed a trocar incisional hernia.

The second most frequent procedure was Nissen fundoplication for gastro-esophageal reflux disease. The mean age of patients undergoing this procedure was 49 years (range 19-68 years). The mean hospital stay was 6 days (range 4-13 days), while the mean BMI was 27.3 (range 19-36). The mean operative time was 166 min (range 60$270 \mathrm{~min}$ ). Associated cholecystectomy was performed in four cases. Two patients required a Nissen redo procedure, and there was one conversion to laparotomy during a Nissen redo because of an esophageal tear.

Gastric banding was the third most common surgical procedure in our series (14 cases). The mean age of patients undergoing this procedure was 41 years (range 2058 years). The mean hospital stay was 4 days (range 37 days), and mean BMI was 41 (range 34-46). The mean operative time was $141 \mathrm{~min}$ (range 90-240 min). One patient had had a previous laparoscopic gastric banding. There was one conversion to laparotomy.

Among the miscellaneous procedures, there were four intra-abdominal tumor resections (three benign cysts and one teratoma), two cholecystectomies, two partial gastric resections and one case of hepatic cyst resection.

A patient's satisfaction was evaluated using a visual ana$\log$ score system: the mean value of functional outcome of the surgical procedure was 8 (range 3-10), and of satisfaction with regard to the entire procedure was 7 (range 2-10). Five patients developed cheloid scars (5\%). Mean followup time for all patients was 11 months (range 15 days to 34 months). Six patients were lost to follow-up (6\%).

\section{Discussion}

Several studies have reported surgical results using the da Vinci robotic system in which this technique has been shown to be applicable and safe [3-9]. No morbidity related to the system has yet been observed. Overall, the reported mortality rate has ranged between 0 and $1.8 \%$, 
while the rate of complication has been less than $10 \%$; conversion to conventional laparoscopy and/or laparotomy was less than 5\%. Almost all studies reported a longer operative time using the robotic system as compared to conventional laparoscopy. Increased overall costs due to longer operative time and the use of more expensive instruments was reported for cases of Nissen fundoplication and colectomy [10-15].

Our team has not experienced the death of a patient during the robotic procedure, and we have observed a morbidity of $3.1 \%$. Conversion to laparoscopy/laparotomy was $5.3 \%$. At the beginning of our learning experience, operative time was long, and although it has diminished with time and experience, it is still longer than conventional laparoscopy. To date, no proven patient-specific advantage of robotic surgery over laparoscopic techniques has been demonstrated. The robotic system allows the surgeon to perform more sophisticated procedures, whereas classical gastrointestinal procedures can be performed safely. The development of mini robots and augmented reality techniques will boost robotic surgery in the future $[9,16]$. We have found that colon and rectum resections, anti-reflux surgery, and obesity surgery were safe and efficacious for the patients.

Several authors have reported good results with colorectal robotic surgery [17-25]. Our experience in terms of operative time, conversion rate, mortality, complications rate and length of stay are similar to those reported in the literature (Table 1). It is our impression that the use of the da Vinci system is from a technical point of view particularly useful for proctectomy with total mesorectum excision (TME) in cases of rectal cancer [25], as lymph node harvesting, nerve sparing and anatomical TME is enhanced by the three-dimensional vision of the pelvis. As reported by others, we prefer to do a hybrid procedure (conventional laparoscopic inferior mesenteric high vessel ligature and splenic flexure take down) and robotic proctectomy with TME [6]. This approach prevents a prolonged operative time and the unnecessary displacing of the robot. Right colectomy for cancer with primary vessels ligation can be performed robotically with great ease; at the end of the procedure, the anastomosis is performed outside the abdomen. Sigmoidectomy for benign disease can also be performed easily as no high vascular ligature is necessary and the splenic flexure is left in place. The operative time for a right colectomy is shorter than that for a left colectomy [24].

Given the limited space for dissection and the need to mobilize the great gastric curvature, robotic Nissen fundoplication and other anti-reflux techniques have been often performed [3-4, 6, 11-13, 26-32]. The surgical outcome of our series is in line with other reports as shown in Table 2. Randomized controlled trials have demonstrated that conventional Nissen fundoplication give similar results to the robotic approach, but it is less expensive and less time consuming [11-13, 32]. Cost analysis should be performed in each country as health systems are differ significantly.

It has recently been suggested that the use of the da Vinci robotic system is valuable for obesity surgery, specifically in cases of gastric banding [3, 7, 29, 33-35] and gastric bypass surgery [36, 37]. Our current experience in obesity surgery is associated with gastric banding devices. The surgical outcome is shown in Table 3 . The totally robotic Roux-en-Y gastric bypass is feasible and safe, but this technique is still being evaluated and compared to

Table 1 Literature survey of robotic colon and rectum surgery

\begin{tabular}{|c|c|c|c|c|c|c|c|}
\hline Author & Year & $\begin{array}{l}\text { Number } \\
\text { of cases }\end{array}$ & $\begin{array}{l}\text { Mean operative } \\
\text { time, minutes } \\
\text { (range) }\end{array}$ & $\begin{array}{l}\text { Conversion } \\
(\%)\end{array}$ & $\begin{array}{l}\text { Mortality } \\
(\%)\end{array}$ & $\begin{array}{l}\text { Complications } \\
(\%)\end{array}$ & $\begin{array}{l}\text { Mean length of } \\
\text { hospital stay, } \\
\text { days (range) }\end{array}$ \\
\hline Delaney et al. [18] & 2003 & 6 & $217(170-270)$ & 16.6 & 0 & 0 & $3(2-5)$ \\
\hline Giulanotti et al. [6] & 2003 & 16 & $202(150-360)$ & 0 & 0 & 0 & NA \\
\hline Anvari et al. [19] & 2004 & 10 & $155 \pm 13.6$ & 0 & 0 & 10 & NA \\
\hline D'Annibale et al. [20] & 2004 & 53 & $240 \pm 61$ & 3.7 & 0 & 7.5 & $10 \pm 4$ \\
\hline Hanly and Talamini [28] & 2004 & 35 & 177 & 14.2 & NA & NA & NA \\
\hline Hubens et al. [29] & 2004 & 8 & $124(87-144)$ & 0 & 0 & 37.5 & NA \\
\hline Woeste et al. [21] & 2005 & 6 & $236 \pm 5.8$ & 16.6 & 0 & 16.6 & NA \\
\hline Bodner et al. [7] & 2005 & 14 & 310 & 0 & 0 & 0 & NA \\
\hline Braumann et al. [22] & 2005 & 5 & $201(80-300)$ & 40 & 0 & 0 & $13.6(9-14)$ \\
\hline DeNoto et al. [23] & 2006 & 11 & $195(145-345)$ & 9 & 0 & 0 & $3.4(3-4)$ \\
\hline Rawlings et al. [24] & 2006 & 30 & $\begin{array}{l}\text { RC } 177(103-306) \\
\text { LC } 225(147-283)\end{array}$ & 6.6 & 0 & 20 & $\begin{array}{l}\text { RC } 5.2(2-27) \\
\text { LC } 6(3-30)\end{array}$ \\
\hline Pigazzi et al. [25] & 2006 & 6 & $280(200-330)$ & 0 & 0 & 16.6 & $4.5(3-11)$ \\
\hline Current series & 2007 & 40 & $162(60-330)$ & 12.5 & 0 & 5 & $9(3-24)$ \\
\hline
\end{tabular}

NA, Not available 
Table 2 Literature survey of robotic Nissen fundoplication

\begin{tabular}{|c|c|c|c|c|c|c|c|}
\hline Author & Year & $\begin{array}{l}\text { Number } \\
\text { of cases }\end{array}$ & $\begin{array}{l}\text { Mean operative } \\
\text { time, minutes } \\
\text { (range) }\end{array}$ & $\begin{array}{l}\text { Conversion } \\
(\%)\end{array}$ & $\begin{array}{l}\text { Mortality } \\
(\%)\end{array}$ & $\begin{array}{l}\text { Complications } \\
(\%)\end{array}$ & $\begin{array}{l}\text { Mean length } \\
\text { of stay, hours } \\
\text { (range) }\end{array}$ \\
\hline Cadière et al. [3] & 2001 & 36 & $82(54-125)$ & 5.5 & 0 & 0 & $2(1-4)$ \\
\hline Chitwood et al. [4] & 2001 & 14 & $107 \pm 3.2$ & 0 & 0 & 0 & NA \\
\hline Giulanotti et al. [6] & 2003 & 49 & $110(40-300)$ & 2 & 0 & 5 & 4 \\
\hline Benincà et al. [23] & 2003 & 13 & $97.1(77-126)$ & 0 & 0 & 7.6 & $3.2(2-7)$ \\
\hline Hanly and Talamini [28] & 2004 & 57 & 192 & 22.8 & 0 & NA & NA \\
\hline Hubens et al. [29] & 2004 & 9 & $100(83-139)$ & 0 & 0 & NA & NA \\
\hline Anvari et al. [30] & 2005 & 13 & $73(45-90)$ & NA & 0 & NA & NA \\
\hline D'annibale et al. [20] & 2006 & 21 & $140(60-240)$ & 0 & 0 & 9.5 & $7.6(4-11)$ \\
\hline El Nakadi et al. [11] & 2006 & 9 & $137 \pm 12$ & 11.1 & 0 & 11.1 & $4.4 \pm 0.2$ \\
\hline Morino et al. [12] & 2006 & 25 & $131.3(90-162)$ & 8 & 0 & 0 & $3(2-6)$ \\
\hline Müller-Stich et al. [13] & 2007 & 20 & $88(60-150)$ & 0 & 0 & 0 & $2.9 \pm 0.8$ \\
\hline Heemskerk et al. [15] & 2007 & 11 & 220 & 0 & 0 & 9 & 4 \\
\hline Current series & 2007 & 31 & $166(60-270)$ & 3.3 & 0 & 3.3 & $6(4-13)$ \\
\hline
\end{tabular}

NA, Not available

Table 3 Literature survey of robotic gastric banding

\begin{tabular}{|c|c|c|c|c|c|c|c|}
\hline Author & Year & $\begin{array}{l}\text { Number } \\
\text { of cases }\end{array}$ & $\begin{array}{l}\text { Mean operative } \\
\text { time, minutes } \\
\text { (range) }\end{array}$ & $\begin{array}{l}\text { Conversion } \\
(\%)\end{array}$ & $\begin{array}{l}\text { Mortality } \\
(\%)\end{array}$ & $\begin{array}{l}\text { Complications } \\
(\%)\end{array}$ & $\begin{array}{l}\text { Mean length } \\
\text { of stay, days } \\
\text { (range) }\end{array}$ \\
\hline Cadière et al. [3] & 2001 & 10 & $60(55-90)$ & 0 & 0 & 0 & $2(2-3)$ \\
\hline Mühleman et al. [33] & 2003 & 6 & $137(11-175)$ & 0 & 0 & 0 & NA \\
\hline Jacobsen [34] & 2003 & 32 & $105(60-150)$ & 0 & 0 & 3.1 & $1(0.2-6)$ \\
\hline Nguyen [35] & 2004 & 2 & NA & NA & 0 & NA & NA \\
\hline Hubens et al. [29] & 2004 & 7 & NA & NA & 0 & NA & NA \\
\hline Bodner et al. [7] & 2005 & 10 & 167 & 0 & 0 & 0 & NA \\
\hline Current series & 2007 & 14 & $141(90-240)$ & 12.5 & 0 & 5 & $4(3-7)$ \\
\hline
\end{tabular}

NA, Not available

conventional laparoscopy, although it seems promising in terms of surgical outcome and BMI reduction [36, 37].

Da Vinci robotic use is being developed in foregut surgery, i.e. Heller myotomy and gastric cancer resections [38-40]. Future developments will include technologies of information systems, virtual reality, and micro-robotics [41].

In conclusion, our preliminary experience with 94 cases is very encouraging. The da Vinci system is safe. Surgical outcome is good and patients' satisfaction is rated high. Future developments in gastrointestinal robotic surgery should include cost analysis studies and evaluations of quality of life outcomes.

\section{References}

1. Mouret P (1996) How I developed laparoscopic cholecystectomy. Ann Acad Med 25(5):744-747
2. Himpens J, Leman G, Cadière GB (1998) Telesurgical laparoscopic cholecystectomy. Surg Endosc 12(8):1091

3. Cadière GB, Himpens J, Germay O (2001) Feasibility of robotic laparoscopic surgery: 146 cases. World J Surg 25(11):1467-1477

4. Chitwood WR, Nifong LW, Chapman WHH (2001) Robotic surgical training in an academic institution. Ann Surg 234(4):475486

5. Perez A, Zinner MJ, Ashley SW, Brooks DC, Whang EE (2003) What is the value of robotic technology in gastrointestinal surgery? Surg Endosc 17(5):811-813

6. Giulanotti PC, Coratti A, Angelini M (2003) Robotics in general surgery. Arch Surg 138(7):77-784

7. Bodner J, Augustin F, Wykypiel H (2005) The da Vinci robotic system for general surgical applications: a critical interim appraisal. Swiss Med Wkly 135(45-46):674-678

8. D'Annibale A, Orsini C, Morpurgo E, Sovernigo G (2006) Robotic surgery: considerations after 250 procedures. Chit Ital 58(1):5-14

9. Ballantyne GH (2007) Telerobotic gastrointestinal surgery: phase 2-safety and efficacy. Surg Endosc 21(7):1054-1062

10. Gutt CN, Oniu T, Mehrabi A, Kashifi A, Schemmer P, Büchler MW (2004) Robot-assisted abdominal surgery. Br J Surg 91(11):1390-1397 
11. El Nakadi I, Mélot C, Closset J (2006) Evaluation of da Vinci Nissen fundoplication clinical results and cost minimization. World $\mathbf{J}$ Surg 30(6): 1050-1054

12. Morino M, Pellegrino L, Giaccone C, Garrone C, Rebecchi F (2006) Randomized clinical trial of robot-assisted versus laparoscopic Nissen fundoplication. Br J Surg 93(5):553-558

13. Müller-Stich BP, Reiter MA, Wente MN (2007) Robot-assisted versus conventional laparoscopic fundoplication: short-term outcome of a pilot randomized controlled trial. Surg Endosc 21(10):1800-1805

14. Rawlings AL, Woodland JH, Vegunta RK, Crawford DL (2007) Robotic versus laparoscopic colectomy. Surg Endosc 21(10): 1701-1708

15. Heemskerk J, van Gemert WG, Greve JW, Bouvy ND (2007) Robot-assisted versus conventional laparoscopic Nissen fundoplication. Surg Laparosc Endosc Percutan Tech 17(1):1-4

16. Taylor GW, Jayne DG (2007) Robotic applications in abdominal surgery: their limitations and future developments. Int J Med Robotics Comput Assist Surg 3:30-34

17. Weber PA, Merola S, Wasielewski A, Ballantyne GH (2002) Telerobotic-assisted laparoscopic right and sigmoid colectomies for benign disease. Dis Colon Rectum 45(12):1689-1696

18. Delaney CP, Lynch AC, Senagore AJ, Fazio VW (2003) Comparison of robotically performed and traditional laparoscopic colorectal surgery. Dis Colon Rectum 46(12):1633-1639

19. Anvari M, Birch DW, Bamehriz F, Gryfe R, Chapman T (2004) Robotic-assisted laparoscopic colorectal surgery. Surg Laparosc Endosc Percutan Tech 14(6):311-315

20. D'Annibale A, Morpurgo E, Fiscon V (2004) Robotic and laparoscopic surgery for treatment of colorectal diseases. Dis Colon Rectum 47(12):2161-2168

21. Woeste G, Bechstein WO, Wullstein C (2005) Does telerobotic assistance improve laparoscopic colorectal surgery? Int J Colorectal Dis 20(3):253-257

22. Braumann C, Jacobi CA, Menenakos C, Borchert U, Rueckert JC, Mueller JM (2005) Computer-assisted laparoscopic colon resection with the da Vinci system: our first experiences. Dis Colon Rectum 48(9):1820-1827

23. DeNoto G, Rubach E, Ravikumar TS (2006) A standardized technique for robotically performed sigmoid colectomy. J Laparoendosc Adv Surg Tech 16(6):551-556

24. Rawlings AL, Woodland JH, Crawford DL (2006) Telerobotic surgery for right and sigmoid colectomies: 30 consecutive cases. Surg Endosc 20(11):1713-1718

25. Pigazzi A, Ellenhorn JDL, Ballantyne GH, Paz IB (2006) Roboticassisted laparoscopic low anterior resection with total mesorectal excision for rectal cancer. Surg Endosc 20(10):1521-1525
26. Chapman WH, Young JA, Albrecht RJ (2001) Robotic Nissen fundoplication: alternative surgical technique for the treatment of gastroesophageal reflux disease. J Adv Laparoendosc Adv Surg Tech 11(1):27-30

27. Benincà G, Garrone C, Rebecchi F, Giaccone C, Morino M (2003) Chirurgia laparoscopica robot-assistita. Risultati preliminary del nostro centro. Chir Ital 55(3):321-331

28. Hanly EJ, Talamini MA (2004) Robotic abdominal surgery. Am J Surg 188(suppl):19S-26S

29. Hubens G, Ruppert M, Balliu L, Vaneerdeweg W (2004) What have we learnt after two years working with the da Vinci robot system in digestive surgery? Acta Chir Belg 104(6):609-614

30. Anvari M, McKinley C, Stein H (2005) Establishment of the world first telerobotic remote surgical service. Ann Surg 241(3):460-464

31. D’Annibale A, Orsini C, MOrpurgo E, Sovernico G (2006) La chirurgia robotica. Conisderazioni dopo 250 interventi. Chir Ital 58(1):5-14

32. Heemskerk J, van Gmert WG, Greve JW, Bouvy ND (2007) Robot-assisted versus conventional laparoscopic Nissen fundoplication. Surg Laparosc Endosc Percutan Tech 17(1):1-4

33. Mühlemann G, Klaus A, Kirchmayr W (2003) Da Vinci roboticassisted bariatric surgery: is it justified in a routine setting. Obes Surg 13(6):848-854

34. Jacobsen G, Berger R, Horgan S (2003) The role of robotic surgery in morbid obesity. J Laparoendosc Adv Surg Tech 13(4):279-283

35. Nguyen NT, Hinojosa MW, Finley D, Stevens M, Paya M (2004) Application of robotics in general surgery: initial experience. Am Surg 70(10):914-917

36. Parini U, Fabozzi M, Brachet Contul R (2006) Laparoscopic gastric bypass performed with the da Vinci intuitive robotic system: preliminary experience. Surg Endosc 20:1851-1857

37. Mohr CJ, Nadzam GS, Alami RS, Snachez BR, Curet MJ (2006) Totally robotic Roux-en-Y gastric bypass: results from 75 patients. Obes Surg 16(6):690-696

38. Kakeji Y, Konishi K, Ieiri S (2006) Robotic laparoscopic distal gastrectomy: a comparison of the da Vinci and Zeus systems. Int J Med Robot Comput Ass Surg 2(4):299-304

39. Iqbal A, Haider M, Desai K (2006) Technique and follow-up of minimally Heller myotomy for achalasia. Surg Endosc 20(3):394 401

40. Anderson C, Ellenhorn J, Hellan M, Pigazzi A (2007) Pilot series of robot-assisted laparoscopic subtotal gastrectomy with extended lymphadenectomy for gastric cancer. Surg Endosc 21(9):16621666

41. Satava RM (2006) Looking forward. Surg Endosc 20:S503-S504 